\title{
Ecological Worldview among Health Care Professionals in Sweden
}

\author{
Marita Wallhagen ${ }^{1}$ and Peter Magnusson ${ }^{2,3 *}$ \\ ${ }^{1}$ Department of Building Engineering, Energy Systems and Sustainability Science, University of Gävle, Sweden \\ ${ }^{2}$ Centre for Research and Development, Uppsala University/Region Gävleborg, Sweden \\ ${ }^{3}$ Cardiology Research Unit, Department of Medicine, Karolinska Institutet, Sweden
}

Submission: December 13, 2021; Published: January 6, 2022

*Corresponding author: Peter Magnusson, Cardiology Research Unit/ Department of Medicine, Karolinska Institutet, Institution of Medicine, Solna, SE-171 76 Stockholm, Sweden

Abstract

Objective: Health care sector and its organizations are responsible for large environmental impacts. Therefore, it is of interest for the sectors key actors, the health care professionals, to act more pro-environmental. Environmental attitudes and values are underlying factors for pro-environmental behavior. However, little is known about these factors among health care professionals and therefore need to be assessed.

Methods and Results: In this study the ecological world view among nurses and physicians were evaluated using the validated New Environmental Paradigm (NEP) survey, 172 respondents (mean age 42 years, 81\% females). The overall mean NEP-score was 3.92; specialist physician (3.96), residency physician (3.54), and nurses (3.99). The NEP-score was significantly higher among specialist physician than residency physicians ( $\mathrm{p}=0.006)$, and between nurses and residency physicians ( $\mathrm{p}=0.001)$.

Conclusion: The overall score was higher than representatives' samples, but lower than environmentalists, indicating a potential for influencing the ecological world view to promote pro-environmental behavior in the health care sector.

Keywords: Ecological; environmental paradigm; environmental value; health care, pro-environmental behavior

\section{Introduction}

Human actions is a threat to the ecosystems to maintain sustainable life conditions locally and in the long-term globally [1]. The understanding and influence of collective behavior are crucial in order to achieve the goals in the Paris Agreement on Climate Change $[2,3]$. This collective behavior is built up of individuals whose attitude emerges from a complex interplay of personal traits, socioeconomic factors, education, political ideology, and cultural context $[4,5]$.

The environmental values and attitudes can be viewed as a social paradigm of individuals in a societal group [6]. There is a belief that paradigms constitute a framework for justifying the mode of action. It is commonly stated that a pro-environmental, or the opposite, anti-environmental behavior stems from underlying values, attitudes, and beliefs in a societal context $[7,8]$. Indeed the association has been established between underlying values and behavior [7]. From this perspective it is important to quantitatively measure and interpret environmental attitudes. As these attitudes provide a driving mechanism for decision-making it needs to be addressed.

The New Environmental Paradigm (NEP) scale was constructed to measure individuals' environmental/ecological worldviews on a group level [8]. Each statement in the questionnaire reflects the common concepts of environmental beliefs [9]. From the beginning a 12-item questionnaire was developed but later a 15-item scale was established; every second statement was formulated as positive and negative statements, improved nomenclature, and multiple facets were derived to grasp a wide set of aspects. The following five facets were defined: Human domination over nature, Human exemptionalism, Balance of nature, The risk of ecocrisis, and Limits to growth [10]. The NEP scale has been applied in many settings across the world, although using a couple of variants despite the robustness and high validity of the 15-item scale [11-13]. 
The health of human civilization will rapidly emerge into a challenge because the natural systems are threatened [14]. Human impact on the earth systems processes endanger the earth system's capacity to support humanity, i.e. to stay within the planetary boundaries [15].

A sector contributing to significant negative environmental impact is the healthcare sector, which for example is a major contributors to environmental pollution contributing to pathological, chemical, pharmaceutical, radioactive, health risk and other wastes $[16,17]$. Many of the interventions necessary for greening healthcare are linked to decision-making, compliance of regulations and waste management schemes, as well as health care staff behavior. Here, Whitmee et al. [14] (p. 2) conclude that "health professionals have an essential role in the achievement of planetary health: working across sectors to integrate policies that advance health and environmental sustainability, tackling health inequities, reducing the environmental impacts of health systems, and increasing the resilience of health systems and populations to environmental change." From this perspective, the health care clinicians' environmental attitudes it is of certain interest for the health care sector. A health consciousness is an underlying factor for both pro-environmental behavior and health behavior [18]. Thus, health care clinicians who promote health are possible motivated to take action regarding environmental considerations. Nevertheless, the knowledge about their underlying attitudes towards environmental issues remains limited.

However, even though numerous studies using NEP have been conducted on diverse populations, both geographically and categories, there is a lack of knowledge about environmental attitudes among healthcare professionals measured with the NEPscale. In order to address this gap, the aim of this study was to examine the NEP-score among healthcare professionals working as clinicians

The following research questions were addressed:

a) Mean NEP score among health care professionals including categories (manager, nurse, residency physician, specialist physician).

b) Mean NEP score with regard to gender differences.

c) Mean NEP score with regard to different categories of health care professionals.

d) Analysis of hypothesized facets of NEP.

\section{Materials and Methods}

\section{Data Collection}

A digital web survey of the 15 scaled NEP-questionnaire translated into the Swedish language (English version as Appendix), was e-mailed to all employees with a clinical background at the internal medicine and cardiology clinics in Region Gävleborg, Sweden. In total, the mail was sent to 518 individuals, followed by one email reminder, between September and December 2017. The email contained information about the purpose of the study, stressed voluntary participation, and provided information with regard to handling of data.

\section{Statistical analyses}

The answers to each question were addressed as a five-point Likert ordinal scale. The five response alternatives were as follows: "strongly agree", "mildly agree", "unsure", "mildly disagree", and "strongly disagree". These items were ordered from one to five and the reversed for every second question. The interpretation of this implies the higher number the more pro-environmental attitude. Concordance with items with odd numbers and disagreement with the even numbered items suggest pro-NEP responses, i.e., scale for odd numbered questions: $1=$ =strongly disagree, $2=$ mildly disagree, $3=$ unsure, $4=$ mildly agree, $5=$ strongly agree; thus, with a reverted scale for even numbered questions.

The complete dataset was imported to SPSS version 22 (IBM, Armonk, NY, USA) and Excel 2010 (Microsoft Corporation, Redmond, WA, USA). Data was reported as numbers, percentages, means including standard deviations (SD), medians, and percentiles when appropriate. Comparisons of continuous variables of means applied a $t$-test. Categorical variables were analyzed using the chi-squared test. A two-sided $p$-value $<0.05$ was considered as statistically significant.

\section{Patient and public involvement}

No patient involved.

\section{Results}

The survey was completed by 172 respondents $(n=139 ; 80.8 \%$ females). Mean age was 42.2 years (SD 12.0) (minimum 21 years, maximum 71 years) and similar between gender (females 42.3 years SD 11.6 vs males 41.6 years SD 13.5). The vast majority were nurses $(n=116 ; 67.4 \%)$ followed by specialist physicians $(n=26$; $15.1 \%)$, residency physicians $(n=23 ; 13.4 \%)$, and managers $(n=7$; $4.1 \%)$.

The mean NEP-score for the cohort was 3.92 (SD 0.46). It ranged from 2.27 to 4.93 and the 25 th, 50 th, and 75 th percentiles were $3.6,3.93$, and 4.27 , respectively.

The mean score was significantly higher, using t-test, among females than males ( 3.98 SD 0.43 vs 3.69 SD 0.53 ; $p=0.423$ ). Facet 1 was highly significant $(p<0.0001)$, Facet $3(p=0.016)$ and Facet 4 $(\mathrm{p}=0.033)$ significant while facet $2(\mathrm{p}=0.177)$ non-significant, and Facet $5(\mathrm{p}=0.058)$ were borderline with regard to gender. In facet 1, all questions were significant. In Facet 2 question 9 and 14 were significant. In the remaining questions one out of three questions were significant. The cohort was divided into three age-strata: 20 35 years, 36-50 years, and above 50 years; none of these groups scored significantly different from the other.

An analysis based on professional categories showed the 
following scores: specialist physician (3.96 SD 0.48), residency physician (3.54 SD 0.52), nurses (3.99 SD 0.41). There was a significantly higher NEP-score among specialist physician than residency physicians $(\mathrm{p}=0.006)$ and between nurses and residency physicians $(\mathrm{p}=0.001)$ while there was no difference between nurses and specialist physicians $(p=0.729)$.

The distribution of answers to each question for the whole cohort is summarized in Table 1. Question 5 'Humans are severely abusing the environment.' showed the highest mean score 4.60, followed by question 7 'Plants and animals have as much right as humans to exist.' (mean 4.47), and question 9 'Despite our special abilities humans are still subject to the laws of nature.' (mean 4.28). On the contrary, the lowest score (mean 2.26) was attributed to question 6 'The Earth has plenty of natural resources if we just learn how to develop them.' followed by question 14 'Humans will eventually learn enough about how nature works to be able to control it.' (mean 3.44), question 1 'We are approaching the limit of the number of people the Earth can support.' (mean 3.52), and question 2 'Humans have the right to modify the natural environment to suit their needs.' (mean 3.58).

Table 1: New Environmental Paradigm (NEP) scale among health care professionals $(n=172)$. Statements about the Relationship between Humans and the Environment.

\begin{tabular}{|c|c|c|c|c|c|c|c|c|c|c|c|c|}
\hline \multicolumn{13}{|c|}{ Statements about the Relationship between Humans and the Environment } \\
\hline \multirow{2}{*}{$\begin{array}{c}\text { Do you Agree or Disagree } \\
\text { that: }\end{array}$} & \multicolumn{2}{|c|}{ Strongly Agree } & \multicolumn{2}{|c|}{ Mildly Agree } & \multicolumn{2}{|c|}{ Unsure } & \multicolumn{2}{|c|}{ Mildly Disagree } & \multicolumn{2}{|c|}{ Strongly Disagree } & \multirow{2}{*}{ Mean } & \multirow{2}{*}{ SD } \\
\hline & $\mathbf{n}$ & $\%$ & $\mathbf{n}$ & $\%$ & $\mathbf{n}$ & $\%$ & $\mathbf{n}$ & $\%$ & $\mathbf{n}$ & $\%$ & & \\
\hline $\begin{array}{l}\text { 1. We are approaching the limit } \\
\text { of the number of people the } \\
\text { earth can support. }\end{array}$ & 38 & 22.1 & 53 & 30.8 & 50 & 29.1 & 22 & 12.8 & 9 & 5.2 & 3.52 & 1.13 \\
\hline $\begin{array}{l}\text { 2. Humans have the right to } \\
\text { modify the natural environ- } \\
\text { ment to suit their needs. }\end{array}$ & 8 & 4.7 & 32 & 18.6 & 24 & 14 & 69 & 40.1 & 39 & 22.7 & 3.58 & 1.16 \\
\hline $\begin{array}{l}\text { 3. When humans interfere } \\
\text { with nature it often produces } \\
\text { disastrous consequences. }\end{array}$ & 80 & 46.5 & 77 & 44.8 & 8 & 4.7 & 6 & 3.5 & 1 & 0.6 & 4.33 & 0.77 \\
\hline $\begin{array}{l}\text { 4. Human ingenuity will insure } \\
\text { that we do NOT make the earth } \\
\text { unlivable. }\end{array}$ & 6 & 3.5 & 27 & 15.7 & 53 & 30.8 & 56 & 32.6 & 30 & 17.4 & 3.45 & 1.06 \\
\hline $\begin{array}{l}\text { 5. Humans are severely abus- } \\
\text { ing the environment. }\end{array}$ & 114 & 66.3 & 54 & 31.4 & 0 & 0,0 & 1 & 0.6 & 3 & 1.7 & 4.60 & 0.70 \\
\hline $\begin{array}{l}\text { 6. The earth has plenty of nat- } \\
\text { ural resources if we just learn } \\
\text { how to develop them. }\end{array}$ & 50 & 29.1 & 70 & 40.7 & 20 & 11.6 & 22 & 12.8 & 10 & 5.8 & 2.26 & 1.18 \\
\hline $\begin{array}{l}\text { 7. Plants and animals have as } \\
\text { much right as humans to exist. }\end{array}$ & 112 & 65.1 & 42 & 24.4 & 5 & 2.9 & 12 & 7.0 & 1 & 0.6 & 4.47 & 0.89 \\
\hline $\begin{array}{l}\text { 8. The balance of nature is } \\
\text { strong enough to cope with the } \\
\text { impacts of modern industrial } \\
\text { nations. }\end{array}$ & 3 & 1.7 & 7 & 4.1 & 20 & 11.6 & 77 & 44.8 & 65 & 37.8 & 4.13 & 0.90 \\
\hline $\begin{array}{l}\text { 9. Despite our special abilities } \\
\text { humans are still subject to the } \\
\text { laws of nature. }\end{array}$ & 90 & 52.3 & 52 & 30.2 & 18 & 10.5 & 12 & 7.0 & 0 & 0 & 4.28 & 0.91 \\
\hline $\begin{array}{l}\text { 10. The so-called "ecological } \\
\text { crisis" facing humankind has } \\
\text { been greatly exaggerated. }\end{array}$ & 4 & 2.3 & 8 & 4.7 & 29 & 16.9 & 50 & 29.1 & 81 & 47.1 & 4.14 & 1.01 \\
\hline $\begin{array}{l}\text { 11. The earth is like a space- } \\
\text { ship with very limited room } \\
\text { and resources. }\end{array}$ & 46 & 26.7 & 69 & 40.1 & 37 & 21.5 & 15 & 8.7 & 5 & 2.9 & 3.79 & 1.03 \\
\hline $\begin{array}{l}\text { 12. Humans were meant to rule } \\
\text { over the rest of nature. }\end{array}$ & 6 & 3.5 & 14 & 8.1 & 12 & 7 & 48 & 27.9 & 92 & 53.5 & 4.20 & 1.10 \\
\hline $\begin{array}{l}\text { 13. The balance of nature is } \\
\text { very delicate and easily upset. }\end{array}$ & 82 & 47.7 & 68 & 39.5 & 8 & 4.7 & 13 & 7.6 & 1 & 0.6 & 4.26 & 0.90 \\
\hline
\end{tabular}




\section{International Journal of Environmental Sciences \& Natural Resources}

\begin{tabular}{|c|c|c|c|c|c|c|c|c|c|c|c|c|}
\hline $\begin{array}{l}\text { 14. Humans will eventually } \\
\text { learn enough about how nature } \\
\text { works to be able to control it. }\end{array}$ & 6 & 3.5 & 25 & 14.5 & 58 & 33.7 & 53 & 30.8 & 30 & 17.4 & 3.440 & 1.05 \\
\hline $\begin{array}{l}\text { 15. If things continue on their } \\
\text { present course, we will soon } \\
\text { experience a major ecological } \\
\text { catastrophe. }\end{array}$ & 88 & 51.2 & 69 & 40.1 & 11 & 6.4 & 4 & 2.3 & 0 & 0 & 4.4 & 0.71 \\
\hline Total: & 733 & $28 \%$ & 667 & $26 \%$ & 353 & $14 \%$ & 460 & $18 \%$ & 367 & $14 \%$ & 3,92 & 0.46 \\
\hline
\end{tabular}

${ }^{a}$ Question wording: 'Listed below are statements about the relationship between humans and the environment. For each one, please indicate whether you agree or disagree with it:' Agreement with the odd numbered items and disagreement with the even numbered items indicate pro-NEP responses; Scale for odd numbered questions: Strongly disagree $=1$, Mildly disagree $=2$, Unsure $=3$, Mildly agree $=4$, Strongly agree $=5$; reverted scale for even numbered questions. SD, standard deviation.

The largest spread, expressed as SD were among question 6, 2 , and 12 while the lowest spread were among question $5,15,3$.

The five facets of NEP, their means and its distribution of answers, are summarized in Table 2. The facet with the highest

score was 'the risk of an ecocrisis', followed by 'balance of nature' and the lowest score was attributed to 'limits to growth'. The mean score in different facets for men and women was also analysed, as well as for different health care professional categories (Table 3).

Table 2: New Environmental Paradigm (NEP) Scale results among health care professionals ( $n=172$ ) grouped into five hypothesized facets (question grouped into five hypothesized facets).

\begin{tabular}{|c|c|c|c|c|c|c|c|c|c|c|c|c|}
\hline \multicolumn{13}{|c|}{ Question Grouped into Five Hypothesized Facets } \\
\hline \multirow{2}{*}{$\begin{array}{c}\text { Facet } \\
\begin{array}{c}\text { Human domination over } \\
\text { nature }(2.7 .12 .)\end{array}\end{array}$} & \multicolumn{2}{|c|}{ Strongly Agree } & \multicolumn{2}{|c|}{ Mildly Agree } & \multicolumn{2}{|c|}{ Unsure } & \multicolumn{2}{|c|}{ Mildly Disagree } & \multicolumn{2}{|c|}{ Strongly Disagree } & \multirow{2}{*}{$\begin{array}{r}\text { Mean } \\
4.08\end{array}$} & \multirow{2}{*}{$\begin{array}{l}\text { SD } \\
0.78\end{array}$} \\
\hline & 126 & $24.4 \%$ & 88 & $17.1 \%$ & 41 & $7.9 \%$ & 129 & $25.0 \%$ & 132 & $25.6 \%$ & & \\
\hline $\begin{array}{c}\text { Human exemptionalism (4. } \\
\text { 9.14.) }\end{array}$ & 102 & $19.8 \%$ & 104 & $20.2 \%$ & 129 & $25.0 \%$ & 121 & $23.4 \%$ & 60 & $11.6 \%$ & 3.72 & 0.68 \\
\hline Balance of nature (3.8.13.) & 165 & $32.0 \%$ & 152 & $29.5 \%$ & 36 & $7.0 \%$ & 96 & $18.6 \%$ & 67 & $13.0 \%$ & 4.24 & 0.59 \\
\hline $\begin{array}{l}\text { The risk of an ecocrisis ( } 5 . \\
10.15 .)\end{array}$ & 206 & $39.9 \%$ & 131 & $25.4 \%$ & 40 & $7.8 \%$ & 55 & $10.7 \%$ & 84 & $16.3 \%$ & 4.38 & 0.6 \\
\hline Limits to growth (1.6.11.) & 134 & $26.0 \%$ & 192 & $3.2 \%$ & 107 & $20.7 \%$ & 59 & $11.4 \%$ & 24 & $4.7 \%$ & 3.19 & 0.74 \\
\hline
\end{tabular}

The numbers in parenthesis refer to the question included in the facet.

Table 3: Mean scores in the five hypothesized facets of New Environmental Paradigm (NEP) Scale and total mean NEP score among different groups of health care professionals $(n=172)$.

\begin{tabular}{|c|c|c|c|c|c|c|}
\hline \multirow{2}{*}{ Groups } & \multicolumn{5}{|c|}{ Hypothesized Facets } \\
\cline { 2 - 7 } & $\begin{array}{c}\text { Human Domination } \\
\text { over Nature (2. 7. 12.) }\end{array}$ & $\begin{array}{c}\text { Human Exemptional- } \\
\text { ism (4. 9. 14.) }\end{array}$ & $\begin{array}{c}\text { Balance of Na- } \\
\text { ture (3. 8. 13.) }\end{array}$ & $\begin{array}{c}\text { The Risk of an Ecoc- } \\
\text { risis (5. 10. 15.) }\end{array}$ & $\begin{array}{c}\text { Limits to Growth } \\
\text { (1. 6. 11.) }\end{array}$ & $\begin{array}{c}\text { Total Mean } \\
\text { NEP-Score }\end{array}$ \\
\hline Women & 4.25 & 3.76 & 4.3 & 4.44 & 3.14 & 3.98 \\
\hline Men & 3.34 & 3.57 & 3.99 & 4.14 & 3.4 & 3.69 \\
\hline $\begin{array}{c}\text { Specilist } \\
\text { physicians }\end{array}$ & 3.88 & 3.86 & 4.14 & 4.42 & 3.47 & 3.96 \\
\hline $\begin{array}{c}\text { Residency } \\
\text { physicians }\end{array}$ & 3.25 & 3.48 & 3.81 & 4.09 & 3.54 \\
\hline Nurses & 4.31 & 3.74 & 4.34 & 4.42 & 3.16 & 3.99 \\
\hline Managers & 3.71 & 3.71 & 4.43 & 4.57 & 2.95 & 3.88 \\
\hline
\end{tabular}

The numbers in parenthesis refer to the question included in the facet.

\section{Discussion}

Health care professionals, nurses and physicians, express a widespread ecological view according to the well-established NEP-scale. The range, but the $25^{\text {th }}$ percentile 3.60 and the $75^{\text {th }}$ percentile 4.27 show are marked heterogeneity. This underlies the individual mindset, which seems to vary among health care professionals. There is a substantial spread both within and between subcategories of health care professionals. This may explain diverse opinions and decision-making in the health care sector regarding pro-environmental policies within organizations. 
These individual variations should be taken into account when interpreting the mean of 3.92. Nevertheless, mean scores are valuable when comparing samples from other studies.

\section{Health care professionals environmental scores in comparison to other studies}

The NEP-scale has been used for more than 40 years, with development of scaling, wording, number of items and response alternatives, which make comparisons between versions difficult. Hawcroft \& Milfont [12] reviewed 139 cohorts of a total 58,279 individuals, of whom a third (32\%) were university students and $29 \%$ were deemed as representatives of the general population of a country or a geographical region. Notably, no single sample comprised solely healthcare professionals. In fact, the 15-item revised NEP-scale was previously applied in several studies, which allow for comparisons. In a large $(n=922)$ Swedish representative sample with a mean age of 49 years and $48 \%$ males the mean score was 3.67 SD 0.48 [19]. Although our data are about ten years later it can be assumed that healthcare professionals have better pro-environmental attitudes than in the general population, or at least female health care professionals, while males had mean score similar to that (3.69). This is also in line with Norwegian data from a general population cohort of 3,686 individuals with a mean score of 3.69 [20]. Several larger samples of representatives from different countries have been reported as follows: two studies from Canada $(n=178$, mean score $3.67 ; n=457$, mean score 3.67$)$, three studies from the USA $(n=676$, mean score 3.75 ; $n=398$, mean score 3.81; $n=206$, mean score 3.65) [21]. Again, the higher score in our sample is reassuring; the mean score is higher both than previous studies in Swedish, neighbor country Norway and other high-income countries.

The group defined as environmentalists, recruited from members of environmental organizations are expected to comprise perhaps the most pro-environmentally friendly subset. As expected, a high mean score has been measured in this type of settings, even though most sample does not allow direct comparison with our data due to different versions of the survey. Instead, two samples using the 15 -item score should be highlighted. In a Norwegian sample of 2,000 environmentalist the mean score was 4.09 [20] as well as in a much smaller UK sample ( $n=45$, mean 4.22) [22]. From this perspective our sample of health care professionals report a mean score beyond what is possible to achieve among highly selective participants. This can be regarded as the upper limit for improvement.

There are vast experience of evaluation of NEP-score among university students across comparable countries. The 15 -item has been used in a Spanish cohort ( $\mathrm{n}=165$, mean 3.58) [23], German ( $\mathrm{n}=468$, mean 4.08) [24], three cohorts from New Zealand $(n=455$, mean 3.51; $n=1,924$, mean 3.88; $n=224$, mean 3.80) [25], and one from the UK $(n=45$, mean 3.31) [22]. In a multinational sample from diverse continents the mean score ranged from 3.50 to 4.02 [26]. It should be pointed out that students show a bias of younger age and higher proportion of females. Especially female students have notably high scores, for example in German samples [24,26].

\section{Differences between men and women}

In our study women scored significantly higher than men. This striking finding is well known from other studies and supports the belief that women generally have a more pro-environmental behavior than men [27-29]. It is not known if differences can be explained to better perception of environmental burden, educational circumstances, and tolerance among women while studies also suggest an embracement for technological solutions among men that may translate into different views of climate crisis and the solutions [30]. Indeed among Canadians, women expressed more support of biosphere, altruistic values, and antianthropocentrism [9,21].

\section{Differences between health care professional categories}

Nurses had the highest score in our sample, although specialist physicians had almost as high mean score, while residency physicians scored lower. It can be speculated if female sex is a key factor to explain this because a high proportion of nurses are females. Residency physicians have a high working load and many have duties in family life and at the same a high working load. But this also suggest that a long university education per $s e$ is not a guarantee for pro-environmental attitude measured as NEP-score. Teaching and medical schools are believed to be focused on management of patients rather than society aspects and the environment in particular. Physicians are key actor in the development of health care sector not only in direct patient management but also on strategies and policy-making in general why their attitude towards the environment is crucial. Therefore, environmental issues need to be addressed in the continued medical educational activities.

\section{Insights regarding the facets}

The derived facets of the NEP-scale provide insights in the deeper understanding of scores. The highest score was demonstrated by the facet The risk of an ecocrisis (mean 4.38). This facet is comprised of the three questions 5, 10, and 15. Two-thirds strongly agreed (66\%) with the statement Humans are severely abusing the environment, about half strongly disagreed (47\%) with The so-called ecological crisis facing humankind has been greatly exaggerated. and strongly agreed with If things continue on their present course, we will soon experience a major ecological catastrophe (51\%). The facet Limits to growth showed the lowest score (mean 3.19). Interestingly the question with the statement The Earth has plenty of natural resources if we just learn how to develop them, reported the lowest NEP-score (mean 2.26). The interpretation of this could be ecological modernization, "green rationalism" and eco-modernist social theory, in which it is possible to combine ecologically and economically rationality, although it historically has been regarded as contradictory purposes [31]. 
When analyzing the different groups of respondents (men/ women and the health care professional categories (Specialist physician, Residency physician, Nurses, and Manager)) in Table 3 , there was a variation regarding which group that had the highest score in each facet.

\section{NEP scores and pro-environmental behaviour change}

There is a controversy whether environmental attitudes are predominantly acquired during early years before adulthood $[32,33]$. It has been advocated that attitude remain basically unchanged throughout life [34] although there seem to a degree of influence during the life course $[27,35]$. Educational level is a strong determinant for pro-environmental behavior, at least when comparing blue collar workers with groups with longer formal education at school [12]. Less is known about differences among different kind of education and the length of studies, but there are many tools to integrate sustainability dimensions in higher education which are used to a varying degree [36]. The causative pathway remains unknown - maybe a pro-environmental behavior is enhanced during university but a selection of people who enter longer education programs are also likely. Longitudinal study show that sustainability performance among students can be influenced during an education [35]. Other studies has highlighted the "attitude-behaviour gap", meaning that increased knowledge and awareness of environmental issues does not automatically result in more environmental behavior [37]. Undoubtedly, there is a complex interaction of socio-economy, education, cultural matters, and personality traits [13].

\section{Conclusion}

The ecological world-view, expressed as mean NEP-score of 3.92, among nurses and physicians are comparatively high, which is reassuring. Women report a higher score than men. A pro-environmental attitude among healthcare professionals is warranted in order to green the health care sector, face the current environmental challenges and hinder future climate crisis.
Physicians and nurses are key actors in the transition of a more environmental-friendly healthcare sector, which is responsible for a significant environmental impact. In this Swedish setting, the overall score of the NEP-survey indicates that there is a willingness to develop the healthcare sector in a more sustainable direction. Further studies are needed to elucidate if NEP-score correlate with specific actions in the healthcare field. Moreover, factors that may change environmental attitude, and more importantly, the behavior should be addressed in the future, specifically for the health care sector.

\section{Declaration}

\section{Acknowledgment}

We appreciate the support from University of Gävle and Region Gävleborg for funding parts of the research presented here.

\section{Author contribution}

Marita Wallhagen conceived and designed the survey and performed the experiments; Marita Wallhagen and Peter Magnusson developed the design, collected the data, performed the statistical data analyses, interpreted the data, and wrote the article.

\section{Conflicts of interest}

The authors declare no conflict of interest. The sponsors had no role in the design of the study; in the collection, analyses, or interpretation of data; in the writing of the manuscript, and in the decision to publish the results.

\section{Data sharing statement}

All relevant data supporting the conclusions of this article is included within the article.

ORCID: Marita Wallhagen: https://orcid.org/0000-00018413-3975

Peter Magnusson: https://orcid.org/0000-0001-7906-7782.

\section{Appendix A. The questionnaire}

Please select the one answer that best applies.

\section{What is your age?}

years

\section{Are you male or female?}

Male

Female

\section{What is your main profession?}

\section{Manager}

Nurse

Residency physician 


\section{Listed below are statements about the relationship between humans and the environment.}

Do you agree or disagree that: (Strongly agree - Mildly agree - Unsure - Mildly disagree - Strongly disagree)

1. We are approaching the limit of the number of people the Earth can support.

2. Humans have the right to modify the natural environment to suit their needs.

3. When humans interfere with nature it often produces disastrous consequences.

4. Human ingenuity will insure that we do NOT make the Earth unlivable.

5. Humans are severely abusing the environment.

6. The Earth has plenty of natural resources if we just learn how to develop them.

7. Plants and animals have as much right as humans to exist.

8. The balance of nature is strong enough to cope with the impacts of modern industrialnations.

9. Despite our special abilities humans are still subject to the laws of nature.

10. The so-called 'ecological crisis' facing humankind has been greatly exaggerated.

11. The Earth is like a spaceship with very limited room and resources.

12. Humans were meant to rule over the rest of nature.

13. The balance of nature is very delicate and easily upset.

14. Humans will eventually learn enough about how nature works to be able to control it.

15. If things continue on their present course, we will soon experience a major ecologicalcatastrophe.

\section{References}

1. Steffen W, Richardson K, Rockström J, Cornell SE, Fetzer I, et al. (2015) Planetary boundaries: Guiding human development on a changing planet. Science 347(6223).

2. Ostrom E (2012) Nested externalities and polycentric institutions: must we wait for global solutions to climate change before taking actions at other scales? Economic Theory 49(2): 353-369.

3. Savaresi A (2016) The Paris Agreement: a new beginning? Journal of Energy \& Natural Resources Law 34(1): 16-26.

4. Annerstedt van den Bosch M, Depledge MH (2015) Healthy people with nature in mind. BMC Public Health 15: 1232.

5. Huang HP, Yore LD (2005) A comparative study of Canadian and Taiwanese grade 5 children's environmental behaviors, attitudes, concerns, emotional dispositions, and knowledge. Int J Sci Math Educ 1(4): 419-448.

6. Kuhn RG, Jackson EL (1989) Stability of Factor Structures in the Measurement of Public Environmental Attitudes. The Journal of Environmental Education 20(3): 27-32.

7. Disch R (1970) The Ecological Conscience: Values for Survival. Prentice Hall.

8. Dunlap RE, Liere KDV (1978) The New Environmental Paradigm. The Journal of Environmental Education 9(4): 10-19.

9. Stern PC, Dietz T, Guagnano GA (1995) The New Ecological Paradigm in Social-Psychological Context. Environment and Behavior 27(6): 723743.

10. Dunlap RE, Liere KDV, Mertig AG, Jones RE (2000) New Trends in Measuring Environmental Attitudes: Measuring Endorsement of the New Ecological Paradigm: A Revised NEP Scale. Journal of Social Issues 56(3): 425-442.
11. Dunlap RE (2008) The New Environmental Paradigm Scale: From Marginality to Worldwide Use. The Journal of Environmental Education 40(1): 3-18.

12. Hawcroft LJ, Milfont TL (2010) The use (and abuse) of the new environmental paradigm scale over the last 30 years: A meta-analysis. Journal of Environmental Psychology 30(2): 143-158.

13. Wiidegren Ö (1998) The New Environmental Paradigm and Personal Norms. Environment and Behavior 30(1): 75-100.

14. Whitmee S, Haines A, Beyrer C, Boltz F, Capon AG, et al. (2015) Safeguarding human health in the Anthropocene epoch: report of The Rockefeller Foundation-Lancet Commission on planetary health. The Lancet 386(10007): 1973-2028.

15. Lade SJ, Steffen W, de Vries W, Carpenter SR, Donges JF, et al. (2020) Human impacts on planetary boundaries amplified by Earth system interactions. Nature Sustainability 3(2): 119-128.

16. Harhay MO, Halpern SD, Harhay JS, Olliaro PL (2009) Health care waste management: a neglected and growing public health problem worldwide. Trop Med Int Health 14(11): 1414-1417.

17. Ryan-Fogarty Y, O’Regan B, Moles R (2016) Greening healthcare: systematic implementation of environmental programmes in a university teaching hospital. Journal of Cleaner Production 126: 248259.

18. Shimoda A, Hayashi H, Sussman D, Nansai K, Fukuba I, et al. (2020) Our health, our planet: a cross-sectional analysis on the association between health consciousness and pro-environmental behavior among health professionals. International Journal of Environmental Health Research 30(1): 63-74.

19. Eriksson L, Garvill J, Nordlund AM (2006) Acceptability of travel demand management measures: The importance of problem awareness, personal norm, freedom, and fairness. Journal of Environmental Psychology 26(1): 15-26. 
20. Olli E, Grendstad G, Wollebaek D (2001) Correlates of Environmental Behaviors: Bringing Back Social Context. Environment and Behavior 33(2): 181-208.

21. Deng J, Walker GJ, Swinnerton G (2006) A Comparison of Environmental Values and Attitudes Between Chinese in Canada and Anglo-Canadians. Environment and Behavior 38(1): 22-47.

22. Pahl S, Harris PR, Todd HA, Rutter DR (2005) Comparative optimism for environmental risks. Journal of Environmental Psychology 25(1): $1-11$.

23. Amérigo M, González A (2001) Environmental values and beliefs in relation to decisions on ecological dilemmas. Studies in Psychology 22(1): 65-73.

24. Kaiser FG, Hübner G, Bogner FX (2005) Contrasting the Theory of Planned Behavior with the Value-Belief-Norm Model in Explaining Conservation Behavior1. Journal of Applied Social Psychology 35(10): 2150-2170.

25. Milfont TL, Duckitt J (2006) Preservation and Utilization: Understanding the Structure of Environmental Attitudes.

26. Schultz PW, Gouveia VV, Cameron LD, Tankha G, Schmuck P, et al. (2005) Values and their Relationship to Environmental Concern and Conservation Behavior. Journal of Cross-Cultural Psychology 36(4): 457-475.

27. Milbrath LW, Fisher BV (1984) Environmentalists: Vanguard for a New Society. SUNY Press, USA.

28. Rideout BE, Hushen K, McGinty D, Perkins S, Tate J (2005) Endorsement of the New Ecological Paradigm in Systematic and E-mail Samples of College Students. The Journal of Environmental Education 36(2): 15 23.
29. Scott D, Willits FK (1994) Environmental Attitudes and Behavior: A Pennsylvania Survey. Environment and Behavior. 26(2): 239-260.

30. Blocker TJ, Eckberg DL (1997) Gender and Environmentalism: Results from the 1993 General Social Survey. Social Science Quarterly 78(4): 841-858.

31. Öst T (2020) Livsstilsförändringar och \&quot;grön\&quot; teknik : Om relationen mellan ekonomisk och ekologisk rationalitet i miljöpolitiken.

32. Kahn JPH, Kellert SR (2002) Children and Nature: Psychological, Sociocultural, and Evolutionary Investigations. MIT Press, USA.

33. Wells NM, Lekies KS (2006) Nature and the Life Course: Pathways from Childhood Nature Experiences to Adult Environmentalism. Children, Youth and Environments 16(1): 1-24.

34. Gatersleben B, Murtagh N, Abrahamse W (2014) Values, identity and pro-environmental behaviour. Contemporary Social Science 9(4): 374392.

35. Von Haartman R, Sammalisto K, Lozano R, Blomqvist P (2017) A Longitudinal Comparison of Sustainability Learning between Men and Women in Engineering and Nursing Programmes. Sustainability 9(8): 1464.

36. Kapitulčinová D, AtKisson A, Perdue J, Will M (2018) Towards integrated sustainability in higher education - Mapping the use of the Accelerator toolset in all dimensions of university practice. Journal of Cleaner Production 172: 4367-4382.

37. Dhir A, Sadiq M, Talwar S, Sakashita M, Kaur P (2021) Why do retail consumers buy green apparel? A knowledge-attitude-behaviourcontext perspective. Journal of Retailing and Consumer Services 59: 102398.

\section{Your next submission with Juniper Publishers will reach you the below assets}

- Quality Editorial service

- Swift Peer Review

- Reprints availability

- E-prints Service

- Manuscript Podcast for convenient understanding

- Global attainment for your research

- Manuscript accessibility in different formats ( Pdf, E-pub, Full Text, Audio)

- Unceasing customer service

Track the below URL for one-step submission https://juniperpublishers.com/online-submission.php 